\title{
Characterisation and Quantification of Anatomy Concepts in a Standard Clinical Methods Textbook: A Content Analysis Approach
}

\author{
Sekelani S. Banda \\ Department of Medical Education Development, School of Medicine \\ University of Zambia, Lusaka, Zambia, P.O Box 50110, Lusaka, Zambia \\ E-mail: ssbanda@zamnet.zm
}

\begin{abstract}
Aim: To analyse the nature and quantity of anatomy concepts intrinsic in a standard clinical methods textbook, used for teaching medical students clinical methods, in order to identify anatomy concepts to be taught to medical students in preparation.
\end{abstract}

Methods: Five categories of anatomy indicators developed in consultation with and accepted by an international panel of anatomists were used to content analyse the $19^{\text {th }}$ Edition of Hutchinson's Clinical Methods. The five categories were subdivided into two classes designated "General Anatomy Terms" and "Technical Anatomy Terms". The inter-rater reliability of coding instructions was $0.76($ P value $=0.0005)$

Results: A total of 17, 223 recording units were coded of which 10,162 were anatomy indicators and 6,980 were technical anatomy terms. The average total anatomy indicators ratio (TAIR $=$ total anatomy indicators/total recording units) was 0.55 and the technical anatomy terms ratio (TATR $=$ technical anatomy terms/total anatomy terms) was 0.68 respectively. There was variability in requirement for technical anatomical terms between the 17 different chapters in the textbook. Sixty-five anatomy themes emerged from the 17 chapters.

Conclusions: These results suggest that a student cannot benefit sufficiently from Hutchinson's Clinical Methods without substantial knowledge of

Key Words: Anatomy, Content Analysis, Anatomy Indicators, Clinical Methods, anatomy. The implications for medical educationists are that 1) educators must be wary of teaching methods that consider anatomy learning in a superficial and simplistic manner, and 2) educators must ensure that students attain adequate depth and scope of anatomy knowledge before or concurrently to learning clinical methods.

\section{INTRODUCTION}

Medical education reform with regard what and how anatomy is taught has been widespread the world over in the last decade. While there is consensus that anatomy is a necessary foundation science for medical training there is insufficient agreement on the scope and depth of anatomy that should be taught to students to prepare them adequately for clinical practice yet many innovative teaching methods have reduced the time available for anatomy teaching. Have such curricula innovations compromised the scope and depth of anatomy learning as some authors suggest ${ }^{1,2,3}$. Even though educators want students to have sufficient knowledge of anatomy to prepare them for clinical studies there is little evidence in the literature to direct the scope and depth of anatomy teaching ${ }^{4}$. Medical educators need to generate and accumulate this evidence and depart from relying on opinions and expert recommendations alone $e^{4,5}$. On our part we identified clinical methods, that is, history-taking and physical examination, as important elements of clinical practice and asked the question 'what is the quantity and character of anatomy in Hutchinson's Clinical Methods, the standard textbook, used to learn clinical methods at our university and many others?' 
We found content analysis to be suited for our study question and also because of time and budget constraints. Content analysis studies in the $90 \mathrm{~s}$ and e a r l y $2000 \mathrm{~s} \quad \mathrm{~s} \mathrm{~h}$ o w e d $\mathrm{th}$ a $\mathrm{t}$ textbooks/documents/journals could be analysed for content and the results used to inform required interventions ${ }^{6,7,8,9,10,11,12,13}$.

\section{METHODS}

Our content analysis methodology was prepared as described by Krippendorff ${ }^{14}$.

\section{Figure 1 Procedures in Content Analysis (Adapted from Krippendorf, 1980, pg54)}

'Fundamentals of Medicine'. They were all requested to identify, from the electronic copy, all words, phrases, and/or sentences that they would consider an anatomy indicator. The compiled list from all the respondents was then analysed for thematic categories and following five categories emerged:

1. References to body parts using lay terms, e.g. mouth, finger, eye.

2. References to body positions and actions, e.g. anterior, lateral, dorsal, flexion, abduction.

3. Named anatomical structures, e.g. femoral nerve, duodenum, ischium

4. Inflections of anatomical terms which implicate an anatomical structure, e.g. peritonitis, uveitis, arthroscopy.

5. Histology or microscopy terms, e.g. endothelium, leucocytes, macula densa.

Categories 1 and 2 were further classified as "General Anatomy

\section{Developing the Coding Instructions}

In the first instance, we defined an anatomy indicator as any word, phrase or sentence that pointed to the need for anatomical knowledge to comprehend that word, phrase or sentence. We then requested for volunteers from an international professional listserv of anatomists to participate in the pilot phase of our research. The nature of the research was explained to the listserv. Eleven persons volunteered to participate in the pilot (five from United States, three from Africa, two from Europe, and one from Asia). All the volunteers were anatomists and six of them had medical qualifications in addition. Each volunteer was given an electronic copy of 13 pages from the 'history and physical examination' section from the textbook Terms" while 3, 4, 5 were classified "Technical Anatomy Terms". Our volunteers accepted the categorization and classification. The categories and classification helped to develop a coding instructions guide, the

$\left[\begin{array}{l}\text { Analysis } \\ \text { alidation }\end{array}\right]$

\section{Anatomy Research Project "Anatomy Content Analysis Coding Guide"}

The purpose of this exercise is to identify "anatomy indicators" from the sample of the text provided. Anatomy indicators are words or phrases that represent anatomical structures or concepts. Types of anatomy indicators and examples are provided below:

a. Reference to body parts using lay terms e.g., mouth, finger, eye.

b. Body position and actions e.g., right side, anterior, lateral, dorsal, flexion, abduction.

c. Named anatomical structures e.g., femoral nerve, duodenum, ischium. 
d. Inflections of anatomical terms which imply that the anatomical structure is inflamed e.g., peritonitis, uveitis, arthritis.

e. Histological/microscopic terms e.g. endothelium, leucocytes, macula densa.

Key:
(a), (b) = General anatomy terms
(c), (d) and (e) = Technical anatomy terms

\section{Instructions:}

Read the text provided and identify what you consider as anatomy indicators. Underline or highlight (with highlight marker) all (headings and illustrations inclusive) anatomy indicators that you have identified. If the anatomy indicator is a phrase underline or highlight the whole phrase and not each word singly. For each identified anatomy indicator write in ink, above the indicator, TAT for Technical Anatomy Term, or GAT for General Anatomy Term.

\section{Inter-Rater Reliability of the Anatomy Content Analysis Coding Guide}

Two pages were randomly selected from the $20^{\text {th }}$ edition of Hutchinson's Clinical Methods ${ }^{16}$ using a series of random selection procedures. The $20^{\text {th }}$ edition was used in order to reserve the $19^{\text {th }}$ edition $^{17}$, which was in use, for the final content analysis. Our university is in a resource-poor setting and it is not unusual to use textbooks that are over 10 years old or older. First, using a random number table, two of the 17 chapters were selected - chapter 6 (pages 141164) and chapter 12 (pages 339-364). From these page ranges two pages were randomly selected page 138 and 332. The two pages were typed onto A4 plain paper and labeled Sample Material 1 and 2 respectively. These were distributed together with the coding guide. Where a figure existed the words of the legend were used instead. We then invited the four anatomists at our university and four clinicians, one each from the four major specialties (internal medicine, obstetrics and gynaecology, paediatrics and child health, and surgery), to participate in the validation exercise. The first-to-volunteer method was used to select the clinicians when we explained our research to clinicians in clinical departments. The eight raters coded the two pages using the provided coding guide. No prior training was done but the coding instructions were explained to each respondent. The raters identified anatomy indicators and classified them as either a general anatomical term (coded 1) or a technical anatomy indicator (coded 2). The classifications for each indicator by each rater were loaded into Microsoft excel and imported into SPSS (Statistical Package for Social Sciences) version 9. The intraclass correlation coefficient, a measure of inter-rater reliability was then computed. The average measure intra-class was $0.76($ Pvalue $=0.0005)$.

\section{Coding Hutchinson's Clinical Methods $\left(19^{\text {th }}\right.$ Edition)}

Having established the reliability of the coding instructions the author alone coded the textbook over a period of one month. Several coders would be ideal and the intraclass correlation repeated, however our circumstances did not permit. Only one chapter was coded at each session to avoid fatigue and loss of concentration. Sentences and sub-heading were used as recording units. The primary units of analysis were words, phrases, or the whole sentence. For each chapter the total recording units and the total anatomical indicators were counted and used to compute the Total Anatomical Indicators Ratio (TAIR) - the amount of content needing anatomical knowledge to comprehend it (total anatomy indicators/total recording units). Each anatomy indicator was classified as either a general anatomy term or a technical anatomy term and used to compute the Technical Anatomical Terms Ratio (TATR) - The amount of content that was advanced anatomical knowledge in nature (technical anatomy terms/total anatomy terms). Each chapter was also analysed for prevailing anatomy themes using frequency counts and the author's expertise as an anatomist and clinician.

\section{RESULTS}

A total of 17,223 recording units were analysed. The mean of total anatomy indicator ratios $(\mathrm{TAIR}=$ total anatomy indicators/total recording units) was 0.55 and the range was 0.07 to 0.87 . The mean of the technical anatomy ratios (TATR $=$ technical anatomy terms/total anatomy indicators) was 0.62 with a range of 0.22 to 0.85 . The TAIR and TATR distribution and their relationship are shown in figure 2 . 


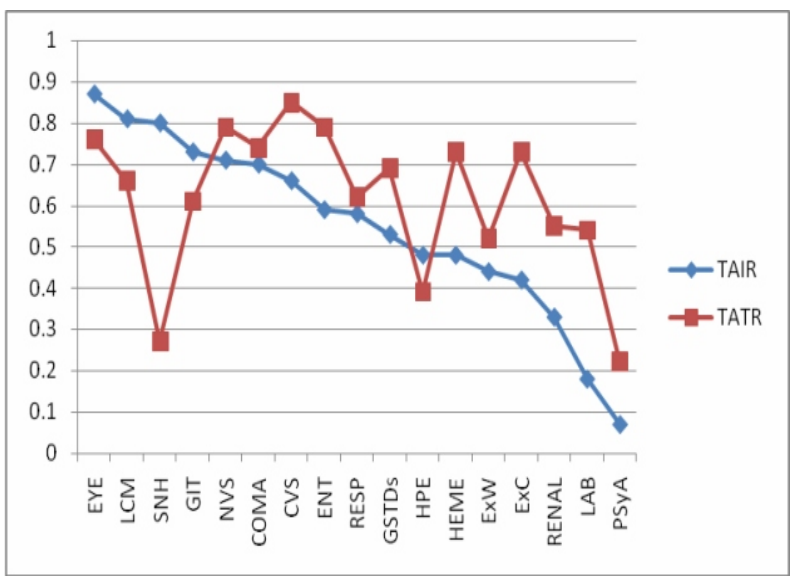

Figure 2 TAIR and TATR by Chapter

TAIR = Total Anatomy Indicators Ratio; TATR = Technical Anatomy Terms Ratio

\section{Chapter Codes}

Eye (Eye); Locomotor system (LCM); Skin, Nails, Hair (SNH); Gastrointestinal system and abdomen (GIT); Nervous system (NVS); The unconscious patient (COMA); Ear, Nose,
Throat (ENT); Respiratory system (RESP); Genitalia and sexually transmitted diseases (GSTDs); History and Physical Examination (HPE); Blood (HEME); Examination of Women (ExW); Examination of children (ExC); Kidneys and Urine (RENAL); Using the Laboratory (LAB); Psychiatric Assessment (PSyA).

Ten of the seventeen chapters had TAIR and TATR of 0.52 or more. The leading five chapter for TAIR were Eye (0.87); locomotor sytem (0.81); skin, nails and hair (0.8), GIT and abdomen (0.73); the nervous system $(0.71)$ while the leading five chapters for TATR were cardiovascular $(0.85)$; nervous system (0.79); ear, nose, throat (0.79); eye (0.76); unconscious patient $(0.74)$; blood, and examination of children each had 0.73 .

A total of 65 anatomical themes were identified from the 17 chapters. The themes are presented in table 2 .

Table 2 - Major Anatomy Themes Found in Hutchinson's Clinical Methods Textbook

\begin{tabular}{|c|c|}
\hline $\begin{array}{l}\text { Clinical Methods } \\
\text { Chapter }\end{array}$ & Major Anatomical Themes \\
\hline The Eye & $\begin{array}{l}\text { 1. Optic fundus and ophthalmoscopic examination } \\
\text { 2. Parts of the eye: eyelids, lacrimal gland, conjunctiva, cornea, iris } \\
\text { 3. Normal relations of the structure of the eye }\end{array}$ \\
\hline $\begin{array}{l}\text { Locomotor } \\
\text { System }\end{array}$ & $\begin{array}{l}\text { 1. Motion at joints: flexion, extension, abduction, adduction, internal rotation, dorsiflexion, plantar } \\
\text { flexion. } \\
\text { 2. Joints: Cervical spine, thoracolumbar spine, sacroiliac joint, shoulder, elbow, wrist, fingers, thumb, } \\
\text { hip, knee, ankle. } \\
\text { 3. Radiological examination of the joints and bones. }\end{array}$ \\
\hline $\begin{array}{l}\text { The Skin, Nails, } \\
\text { \& Hair }\end{array}$ & $\begin{array}{l}\text { 1. Layers of the skin: epidermis, dermis. } \\
\text { 2. Growth stages of hair: anagen, catagen, telogen }\end{array}$ \\
\hline $\begin{array}{l}\text { Gastrointestinal } \\
\text { Tract and } \\
\text { Abdomen }\end{array}$ & $\begin{array}{l}\text { 1. Regions of the abdomen \& organs underlying. } \\
\text { 2. Anterior and posterior surface anatomy of abdominal organs. } \\
\text { 3. Position of common skin incisions. } \\
\text { 4. Superficial veins seen in portal circulation obstruction } \\
\text { 5. Plain and contrast } x \text {-rays of the GIT }\end{array}$ \\
\hline Nervous System & $\begin{array}{l}\text { 1. The motor system: lower motor neurones, corticospinal system, upper motor neurones, extrapyramidal } \\
\text { system, and cerebellum. } \\
\text { 2. Segmental innervation of muscles of the upper and lower limb. } \\
\text { 3. The Sensory system - spinothalamic tracts } \\
\text { 4. Anterior and posterior dermatomes of the body } \\
\text { 5. Blood supply to the brain and spinal cord. } \\
\text { 6. The lobes of the brain and the functional centres. } \\
\text { 7. Cranial nerves: function, clinical disorders, how to examine them. }\end{array}$ \\
\hline
\end{tabular}




\begin{tabular}{|c|c|}
\hline $\begin{array}{l}\text { The Unconscious } \\
\text { Patient }\end{array}$ & $\begin{array}{l}\text { 1. } \\
\text { 2. Prainstem } \\
\text { 3. The tentorium - supra-, trans-, infra- organs and lesions } \\
\text { 4. Intracranial haemorrhage - subarachnoid, subdural, extradural. } \\
\text { 5. Coning: brainstem \& cerebellar herniation } \\
\text { 6. Ocular movements: brainstem, vestibular nuclei, medial longitudinal fasciculi, oculomotor, trochlear, } \\
\text { abducent nerves. }\end{array}$ \\
\hline $\begin{array}{l}\text { Cardiovascular } \\
\text { System }\end{array}$ & $\begin{array}{l}\text { 1. Anatomical landmarks of the chestwall } \\
\text { 2. Locating peripheral pulses: radial, brachial, carotid, femoral, popliteal, posterior tibial, dorsalis paedis. } \\
\text { 3. The cardiac cycle and chambers of the heart. } \\
\text { 4. Auscultation of heart sounds and valvular surface positions. } \\
\text { 5. Congenital abnormalities of the heart: atrial septal defects, ventricular septal defects, patent ductus } \\
\text { arteriosus, Fallot's tetralogy, coarctation of the aorta. } \\
\text { 6. The relationship between myocardial regions, coronary vessels, and ECG. } \\
\text { 7. Radiographic examination of the heart. }\end{array}$ \\
\hline $\begin{array}{l}\text { Ear, Nose } \\
\text { \&Throat }\end{array}$ & $\begin{array}{l}\text { 1. Hearing apparatus axis: external auditory meatus, tympanic membrane, ossicles, oval fenestra, and } \\
\text { cochlea. } \\
\text { 2. Tympanic membrane and auriscope } \\
\text { 3. Middle and inner ears (bony and membranous labyrinthes). } \\
\text { 4. Structure of the nasal vestibule, nasal septum and nasal turbinates. } \\
\text { 5. Olfactory and respiratory mucosa and Little's area. } \\
\text { 6. X-rays showing the paranasal sinuses (frontal, maxillary, ethmoidal, sphenoidal) } \\
\text { 7. Larynx as seen at laryngoscopy } \\
\text { 8. Divisions pharynx: naso-, oro-, laryngo. }\end{array}$ \\
\hline $\begin{array}{l}\text { Respiratory } \\
\text { System }\end{array}$ & $\begin{array}{l}\text { 1. The chest wall } \\
\text { 2. Bronchopulmonary tree } \\
\text { 3. Pleura and pleural spaces } \\
\text { 4. Identifying anatomical structures on chest } \mathrm{x} \text {-rays. }\end{array}$ \\
\hline $\begin{array}{l}\text { Genitalia } \\
\text { and Sexually } \\
\text { Transmitted } \\
\text { Diseases }\end{array}$ & $\begin{array}{l}\text { 1. Examination of The male genitalia: penis, urethral orifice, prepuce, glans, coronal sulcus, scrotum, } \\
\text { testis, epididymis. } \\
\text { 2. Examination of the female genitalia: vulva, labia majora, labia minora, clitoris, urethral orifice, vagina. } \\
\text { 3. Anorectal examination: ischial spines, anus, anal canal, rectum, perineal body, ischiorectal fossa. }\end{array}$ \\
\hline The Blood & $\begin{array}{l}\text { 1. Lymph node groups: head \& neck, axillary, epitrochlear, para-aortic, inguinal, femoral, popliteal. } \\
\text { 2. Sites for venepuncture } \\
\text { 3. Components of blood: cells and fluid }\end{array}$ \\
\hline $\begin{array}{l}\text { Examination of } \\
\text { Women }\end{array}$ & $\begin{array}{l}\text { 1. The cervix } \\
\text { 2. Vagina and vaginal vault } \\
\text { 3. Gravid uterus and abdominal landmarks and foetal parts. } \\
\text { 4. Radiology in women: hysterosalpingography, x-ray pelvimetry, CT scan of pelvis }\end{array}$ \\
\hline $\begin{array}{l}\text { Examination of } \\
\text { Children }\end{array}$ & $\begin{array}{l}\text { 1. Examination of the head: fontanelles, sutures, and head circumference. } \\
\text { 2. Screening for congenital abnormalities. } \\
\text { 3. Developmental milestones }\end{array}$ \\
\hline Kidneys \& Urine & $\begin{array}{l}\text { 1. The structure of the kidney - glomeruli, calyces, renal pelvis. } \\
\text { 2. The general arrangement of the urinary system - glomerulus, renal tubules, calyces, pelvis, ureters, } \\
\text { bladder. } \\
\text { 3. Identification of anatomical structures in intravenous pyelograms. } \\
\text { 4. CT scan of abdomen at kidney level }\end{array}$ \\
\hline $\begin{array}{l}\text { Using the } \\
\text { Laboratory }\end{array}$ & $\begin{array}{l}\text { 1. Obtaining specimens for laboratory investigations: venous blood, arterial blood, pleural fluid, gastric } \\
\text { fluid, peritoneal fluid, cerebrospinal fluid. }\end{array}$ \\
\hline $\begin{array}{l}\text { Psychiatric } \\
\text { Assessment }\end{array}$ & $\begin{array}{l}\text { 1. Lobes of the brain } \\
\text { 2. Visual pathways } \\
\text { 3. Autonomic nervous system } \\
\text { 4. The limbic system }\end{array}$ \\
\hline
\end{tabular}




\section{DISCUSSION}

This was a study of content analysis of a standard clinical methods textbook at our university. The textbook Hutchinson's Clinical Methods is an internationally renowned book and is widely used in the United Kingdom and Africa. We were surprised at the high content of anatomy in a clinical methods textbook (average of TAIRs $=0.55$; TATRs $=0.62$, most chapters had .0.50 TATR). Although there was no other findings in the literature to compare with it would appear that there is a considerable demand for both general and technical anatomical knowledge. Indeed, studies, for example ${ }^{1,2,3}$, that have raised concern about the scope and depth of knowledge of students in innovative curricula may have a basis for their concerns because clearly the anatomy required for clinical methods, which is only one component of activities in the clinical setting that demand knowledge of anatomy, is substantial. Outstandingly, some authors ${ }^{4}$ have advised that planning the structure of an anatomy course should not be based on a single book or recommendation but on evidence. Our study anchors on the quest for evidence and in this case we looked for a purpose-fit when we analysed a foremost resource for learning clinical methods to inform, at least a segment, of anatomy to be learned. The content derived from our thematic catalogue of anatomy does not closely correspond to the AACA regionally-oriented approach $^{18}$. It would be of interest to many scholars to know the process that was used to develop the AACA recommendations.

Indeed, the traditional view was that anatomy should be rightfully a prerequisite to clinical studies. It is already known that anatomy imparts a medical vocabulary to medical students which is important in the transition from basic sciences to clinical sciences. The modern-day view of some scholars is that anatomy can be learned concurrently with clinical studies. In our study it emerged that technical anatomy terms, such, a named anatomical structure (e.g. femoral nerve, ischium), inflections of anatomy terms (e.g. peritonitis, uveitis, arthroscopy) and histology/microscopy terms (e.g. endothelium, leucocytes, macula densa) were predominant (TATR $=0.62$ ). This appears to require a robust repository of anatomical knowledge to benefit from the textbook sufficiently. The inference from this is that the textbook authors either assumed already existing anatomical knowledge or expect the learner to acquire the necessary anatomy concurrently to learning clinical methods. On one hand, the prerequisite approach perpetrates the tendency to consider anatomy as a disparate discipline in its own right for its own sake and on the other the concurrent approach may cause superficial and simplistic learning of anatomy that could prove insufficient and/or ineffective for learning clinical methods. This is a quandary anatomy educators must address. Our findings seem to favour the approaches that are allow serial and sequential learning of anatomy (spiral or longitudinally-orientated curricula) where basic anatomy can be taught and then followed up with applied anatomy. First, the basic anatomy concepts, that is, 1) the structure and function of basic tissue types (muscle, nerve, epithelia, connective tissue), 2) regions of the body, and 3) structure and function of body systems, and then appropriate anatomy later. The appropriate anatomy could be that which the student is expected to learn alongside the clinical materials. General anatomy followed by technical anatomy.

To our knowledge, our study is the first formal content analysis of a clinical methods textbook to investigate the kind of anatomy required for clinical methods learning. There are however, several limitations including reliance on one coder, one textbook and generalizability. However, concerns about the generalizability of our findings, as with other qualitative research, can be replaced with transferability. Transferability refers to the extent to which the results can be generalized or transferred to, in this case, other textbooks of clinical methods. We believe the method we have described can be reproduced by other researchers and applied to another standard textbook of clinical methods.

\section{CONCLUSIONS}

This study has showed that about 55 per cent of content of Hutchinson's Clinical Methods included general and technical anatomy terms. Although we cannot make assumptions about whether the anatomy should be learned a priori or concurrently, our findings indicate that there is a substantial demand, both in scope and depth for knowledge of anatomy, to learn clinical methods sufficiently from the textbook studied. The implications of our 
findings are that medical educators should be wary of curricula innovations that may result in superficial and simplistic learning of anatomy and that, like Grkovic ${ }^{4}$ advised, they should base their curricula plans on evidence rather than expert opinion alone. Our study may have contributed to the pool of evidence for curriculum planners.

\section{REFERENCES}

1. McKeown, P.P., Heylings, D.J., Stevenson, M., McKelvey, K.J., Nixon, J.R., McCluskey, D.R. (2003). The impact of curricular change on medical students' knowledge of anatomy. Medical Education; 37: 954-961.

2. Hinduja, K., Samuel, R., Mitchell, S. (2005). Problem-based learning: is anatomy a casualty? Surgeon; 3:84-87.

3. Nayak, S., Ramnarayan, K., Somayaki, N., Bairy, K.N. (2006). Teaching anatomy in a problem-based learning (PBL) curriculum. Neuroanatomy; 5: 2-3.

4. Grkovic, I., Guic, M.M., Kosta, V, Poljicanin, A., Caric, A., Katarina, V. (2009). Croat Med J; 50: 49-54.

5. Banda, S. S. (2009). The Case Anatomical Knowledge Index (CAKI): A Novel Method Used to Assess Anatomy Content in Clinical Cases. Anatomical Sciences Education; 2(1): 9-18.

6. Buchanan, D., Jordan, S., Preston, D. and Smith, A. (1997). Doctor in the process. The engagement of clinical directors in hospital management. Journal of Management in Medicine, 11(2-3): 132-56.

7. Gottschalk, L. (1999). The application of a computerized measurement of the content analysis of natural language to the assessment of the effects of psychoactive drugs. Methods Findings in Experimental Clinical Pharmacology, 21(2): 133-8.

8. Hogan, D. (1999). Did Osler suffer from "paranoia antitherapeuticum baltimorensis"? A comparative content analysis of The Principles and Practice of Medicine and Harrison's Principles of Internal Medicine, $11^{\text {th }}$ edition. Canadian Medical Association Journal, 161(7): 842-5.
9. Marcdante, K. and Simpson, D. (1999). How pediatric educators know what to teach: the use of teaching scripts. Pediatrics, 104(1 Pt 2): $148-50$.

10. Milidonis, M., Godges, J. and Jensen, G. (1999). Nature of clinical practice for specialists in orthopaedic physical therapy. Journal of Orthopedics Sports Physical Therapy, 29(4): $240-7$.

11. Berth, H. (2001). The measurement of anxiety through computerized content analysis: automation of the Gottschalk-Gleser Test. Psychotherapy Psychosomatic Medical Psychology, 51(1): 10-6.

12. Dejong, W., Wolf, R. and Austin, S. (2001). U.S. federally funded television public service announcements (PSAs) to prevent HIV/AIDS: a content analysis. Journal of Health Communication, 6(3): 249-63.

13. Prystowsky, J. and Bordage, G. (2001). An outcomes research perspective on medical education: the predominance of trainee assessment and satisfaction. Medical Education, 35(4): $331-6$.

14. Krippendorf, K. (1980). Content analysis. SAGE Publications. Newbury Park. ISBN 08039-1498-9.

15. Kaye, D. and Rose, L. (1983). Fundamentals of Internal Medicine. Mosby. St. Louis. ISBN 08016-2622-6.

16. Swash, M. (1989). Hutchinson's Clinical Methods $\left(19^{\text {th }}\right.$ Edition). Bailliere Tindall. London. ISBN 0-7020-1329-3.

17. Swash, M. (1995). Hutchinson's Clinical Methods (20 $0^{\text {th }}$ Edition). W.B. Saunders. London. ISBN 0-7020-2531-3.

18. AACA (1996). A clinical anatomy curriculum for the medical student of the $21^{\text {st }}$ century: Gross anatomy. Education Affairs Committee, American Association of Clinical Anatomists. Clinical Anatomy, 9(2): 71 -99. 